\title{
Digital game elements, user experience and learning: A conceptual framework
}

\author{
Andreas Alexiou $^{1}$ (D) Michaéla C. Schippers ${ }^{2}$
}

Received: 8 December 2017 / Accepted: 26 April 2018 /Published online: 17 May 2018

(C) The Author(s) 2018

\begin{abstract}
The primary aim of this paper is to identify and theoretically validate the relationships between core game design elements and mechanics, user motivation and engagement and consequently learning. Additionally, it tries to highlight the moderating role of player personality traits on learning outcomes and acceptance and suggest ways to incorporate them in the game design process. To that end, it outlines the role of narrative, aesthetics and core game mechanics in facilitating higher learning outcomes through intrinsic motivation and engagement. At the same time, it discusses how player goal orientation, openness to experience, conscientiousness, sensation seeking and need for cognition influence the translation of the gameplay experience into valuable learning outcomes and user acceptance of the technology.
\end{abstract}

Keywords Digital games · Narrative $\cdot$ Mechanics $\cdot$ Learning $\cdot$ Engagement $\cdot$ Personality

\section{Introduction}

We are currently experiencing an increasing virtualization and rather unexpected ludification $^{1}$ of the way we communicate, collaborate, learn, consume or entertain ourselves. The relationship between play and learning, in particular, is one that has been explored both by evolutionary (for a review see Bjorklund and Pellegrini 2010) and developmental psychology (e.g. Jean Piaget 1962; Vygotsky 1978), as well as by recent

${ }^{1}$ The introduction of game elements in non-game applications (from the latin ludus=game).

Andreas Alexiou

A.Alexiou@uva.nl

Michaéla C. Schippers

mschippers@rsm.nl

1 Amsterdam Business School, University of Amsterdam, Amsterdam, the Netherlands

2 Rotterdam School of Management, Erasmus University, Rotterdam, the Netherlands 
studies in neuroscience (e.g. Pellis and Pellis 2007). This significant body of literature has emphasized the positive influence of several dimensions of play on the development of important cognitive, emotional an social competences (Earp et al. 2014; Granic et al. 2014; Qian and Clark 2016). Despite the above encouraging evidence however, educational digital games haven't yet managed to achieve the widespread acceptance of their entertainment counterparts and oftentimes are approached by scholars and educators with skepticism (Miller et al. 1999).

Recent developments in gaming technology, reinvigorated the discussion regarding the potential of digital games as vehicles for learning. Serious Games and Gamification have taken the world by storm the past few years (Takahashi 2013), offering a more game-like educational experience and blurred the line between learning and entertainment even more. There has been a breadth of studies in the past that discussed certain dimensions of digital games and their importance in the gaming experience by looking at the motivational outcomes of gameplay (e.g. Cairns et al. 2013; Erhel and Jamet 2013; Nacke et al. 2010; Qin et al. 2010) and suggested different angles of studying digital games, such as narratives (e.g. Lee et al. 2006), rule-systems (e.g. Juul 2005), or aesthetics (e.g. Smuts 2005). Nevertheless, we are still missing a thorough theoretical understanding of how the different elements embedded in game design influence user experience and learning, something that this paper embarks to do.

In the sections that follow, we will be discussing how game design elements influence player intrinsic motivation and engagement, two theoretically distinct constructs that oftentimes are used in the literature interchangeably. We will therefore theoretically establish the differences between these two constructs, how they relate to each other and how major game elements influence them. Additionally, we will be proposing a set of personality traits as moderating variables in the aforementioned relationships. The role of user dispositions in shaping user experience and learning outcomes has been neglected in the literature, so this part attempts to serve as a foundation for future research in the area.

Existing research has shown that: a) specific game rules and mechanics facilitate the development of cognitive skills such as neural processing and efficiency, spatial skills, enhanced mental rotation abilities, problem solving skills and creativity (Granic et al. 2014), b) narrative elements provide with excellent platforms for thought experiments and simulations of "models of behavior" (Simons 2007), and c) game aesthetics provide with the necessary fidelity and realism that brings the other two aforementioned game layers to life, while enhancing skill and knowledge transfer to offline settings (see Fig. 1). All the aforementioned game elements, however, besides supporting learning, also stimulate user engagement and intrinsic motivation. Narrative elements enhance the emotional engagement of users via empathy and identification with in-game characters, game mechanics regulate the levels of challenge in the game contributing therefore to the cognitive engagement of users, and graphical fidelity assists user control which is an important element of player engagement (Whitton 2010). In addition, the importance of individual differences in accepting and utilizing such applications is recognized. To this front, the paper theoretically discusses how goal orientation, openness to experience, conscientiousness, sensation seeking and need for cognition influence the translation of the gameplay experience into valuable learning outcomes, as well as the user acceptance of the technology. 


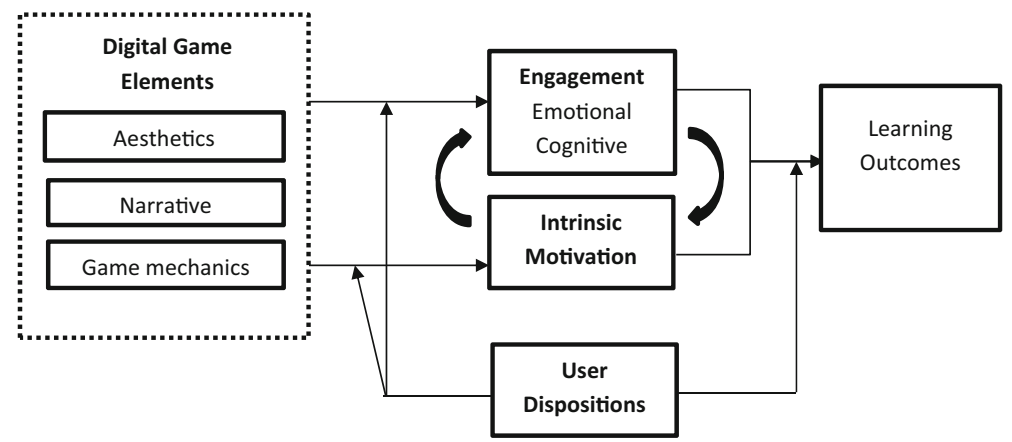

Fig. 1 A conceptual model linking game elements embedded in the instructional design with intrinsic motivation, user engagement and individual dispositions

\section{Digital game-based learning}

Digital games and game-based learning in general have been traditionally associated with the constructivist view on learning as they provide with sandbox environments where players are allowed to experiment and construct meaning out of their cognitive and emotional experiences (Boyle et al. 2011; Kark 2011; Rooney 2012). Under such a view, knowledge is built from within and sensemaking and understanding are intertwined with our interaction with the environment. Cognition has therefore a functional and adaptive role, constantly filtering environmental input during the process of interpretation. Self-regulation, hands-on experience, mindful reflection, social interaction, critical thinking and reasoning are core elements of the constructivist approach. In order to accommodate for these needs, the instructional environment should provide with a complex and relevant representation of the real world, allow for autonomy, experimentation and social negotiation, present authentic tasks and real world scenarios and foster reflective practice (Driscoll 2005; Lainema and Makkonen 2003).

Games are ex vi termini associated with playful imagination -allowing learners to simulate and experiment with real-life scenarios-, social interaction with more capable peers -allowing learners to enhance their cognitive understanding-, and intrinsic motivation - required for sustaining involvement in self-regulating learning over time(Malone and Lepper 1987; Malone 1981). Digital games more than any other technology have the capability to bridge the constructivist learning goals with the constructivist conditions for instruction while controlling to some extent for the potential shortcomings that one-dimensional hands-on and discovery applications may have.

However, one major point of critique for constructivist methods of instructions is the element of minimally guided instruction (Kirschner et al. 2006). The prototypical constructivist approach to teaching, is based on the assumptions that having students construct their own solutions to "authentic" problems results in a more effective learning experience and that knowledge can be best acquired though experience with the methods or processes of the discipline being studied (Kirschner et al. 2006). This approach of minimally guided discovery has been heavily criticized with evidence existing on the contrary (Mayer 2004). Games however can fluctuate considerably between being heavily structured (restricted play) and having no structure at all (free 
play) (Zimmerman and Salen 2003). The problem with heavy structure and frequent corrective feedback is that it can have a negative impact on the engagement of the user (Huang 2011; Moreno 2004) while no structure, high complexity and minimal feedback can lead to high cognitive load and subsequent frustration and disengagement (Brünken et al. 2003; Van Merrienboer and Sweller 2005). As we will be discussing further on, well-designed games implement a method of scaffolding for gradually familiarizing players with the complexity of the virtual. Many times this gradual advancement is coupled with a pattern of narrative that resembles that of the Hero's Journey (Campbell 2003), the classic narrative of the ordinary individual (low skill level) that after receiving the call embarks on a long and perilous journey where through quests and ordeals will transform herself (high skill level) and the world around him. Successful games therefore, by design, dictate a reconciliatory path between guided and minimally guided instruction by using engagement as an indicator of how much freedom the user can handle before they feel frustrated or lose interest.

Secondly, simple hands-on experience doesn't guarantee the deep understanding and cognitive development that constructivism envisions. Rooted in the burgeoning field of cognitive science, constructivism poses that cognitive conflict is the stimulus for learning and determines the organization and nature of what is learnt (Savery and Duffy 1996). The incorporation of new concepts into existing mental models or the development of new ones requires not only a "hands-on" experience, but also a "minds-on" (Pines 1985). Games are designed to allow for the development and testing of various meta-cognitive strategies (Kim et al. 2009). Through a welldesigned system of rules and mechanics, learners can develop cognitive strategies to win the game, but winning strategies require a gradual gain of certain declarative, procedural and strategic (tacit) knowledge (cognitive knowledge). At the same time, during experimentation and practical application of the acquired knowledge, learners enhance particular psychomotor skills such as perception, readiness to act, adaptation etc. (skill-based knowledge).

A game could therefore aspire not only to allow the transfer or construction of knowledge -factual, conceptual, procedural or meta-cognitive- but also to enhance the skills of comprehension, application, analysis, synthesis and evaluation (Krathwohl 2002). In other words, grant the players the ability to a) retrieve relevant knowledge from memory, b) determine the meaning of instructional messages, c) apply a procedure to a given situation, d) identify the constituent parts of the material, how they relate to each other and their role in the overall structure or purpose, e) make judgments based on criteria and standards and f) create something novel out of existing elements (Krathwohl 2002). On top of the above games also generate sets of emotional cues that the learner assigns to different phenomena enhancing the way they internalize values (moral, social or political) or respond to situations (affective knowledge).

Overall, despite occasional critique, existing evidence has shown that digital games are a promising and capable medium for instruction and learning across contexts and age groups (Clark et al. 2016; DeSmet et al. 2014; Merchant et al. 2014). Unfortunately, relevant literature on the game dimensions that enhance learning, user experience and human computer interaction remains fragmented. In order to open the black box of game-based learning and provide a road-map for future research and practice, this paper will synthesize findings and theory and provide with an integrative framework of digital game-based learning. 


\section{Game design and engagement}

User engagement is one of the most prominent qualities of digital games, to the extent that a considerable body of literature studies player behaviors that border with that of pathological addiction (Gentile 2009). The cognitive and emotional engagement of players are a function of game elements that are nested within three main layers: the game system (rules, mechanics), narrative (theme, story, characters) and aesthetics (audiovisual elements, fidelity, aesthetic choices). When it comes to learning applications, cognitive engagement refers primarily to the focus of attention, while emotional engagement stresses the role of emotions and feelings in supporting the desired cognitive processes. Unfortunately, the role of emotions in the learning process, while important, is not often accounted for (Fredricks et al. 2004). The reason that we apply a distinction between emotional and cognitive engagement is in order to more accurately separate and discuss the effect of certain game elements on generating those affective reactions (e.g. boredom, happiness, interest, anxiety) that will eventually support or hinder the actual psychological investment in learning (e.g. going beyond the requirements, preference for challenge, being-strategic or self-regulating) (Fredricks et al. 2004).

\subsection{Game system design and user engagement}

The game system incorporates a set of rules and mechanics that determine the degrees of freedom that players have during gameplay and define the laws that govern the virtual environment. For the purpose of this paper four design elements are discussed, that are expected to have the major influence on the level of engagement that players experience: goals, rewards, feedback, and challenge (Hamari et al. 2016; Plass et al. 2015; Ronimus et al. 2014; Tsai et al. 2015).

\subsubsection{Goals and rewards}

Goal setting in digital games is typically implemented through a system of objectives, quests and sub-quests which grow more challenging as the game progresses and oftentimes operate on a parallel fashion. Previous research has shown that game goals that are clear, specific, and challenging can generate greater persistence and enhanced performance on behalf of the players (Locke and Latham 2004; Locke et al. 1981). At the same time, digital games are capable of deploying an array of mechanisms that generate a perception of progress towards attaining each goal and the associated reward. Experience has shown that gamers tend to be more engaged towards achieving a particular goal when they have the sense that they are gradually moving towards it (Lewis-Evans 2013). Such a behavior is in line with the behaviorist theory of goalgradient, that predicts that subjects expend more effort as they approach a reward (Kivetz et al. 2006). Therefore, the existence of proximal goals, building up to larger prospective ones, enhances the engagement levels of users in two ways. They provide with immediate incentives that deter players from temporizing and getting detached from the distant goal through clear and attainable sub-goals, and reinforce self-efficacy by providing players with indicants of mastery as sub-goals get gradually achieved (Bandura and Schunk 1981). 
The reward systems implemented in digital games are another important source of player engagement (Reeves and Read 2009). Reward systems can be fairly complex and variable and are typically associated with players' effort, progress and performance. Existing evidence has linked rewards to engagement (e.g. McKernan et al. 2015) however certain types of rewards have been found to have a higher impact on the cognitive engagement of players. In particular, gamers tend to prefer unpredictable rewards over steady and predictable ones (Howard-Jones and Demetriou 2008). A great example of this mechanic is the "loot drops" that can be found in many commercially successful games like Diablo or World of Warcraft. Such a mechanic regulates the ingame value of the reward that a player will receive after defeating an enemy based on some pre-determined probability. Such rewards are associated with higher levels of dopamine in the brain that results in higher pleasure and are in part responsible for the compulsive behavior that is oftentimes observed in gamers (Howard-Jones and Demetriou 2008). Although the relationship between such reward systems and the levels of pleasure experienced seems counter-intuitive at first, from an evolutionary theory standpoint it could be justified. In a "state of nature" and in particular in situations of high unpredictability (i.e. a novel environment) the cognitive processing of information is rendered ineffective (Anselme 2013). In such a situation the inability to make the correct prediction based on cognition is compensated with the utilization of a motivational process that would stimulate action through the release of dopamine as a reward for such a behavior (Anselme 2013). In other words, the brain rewards daring and acting in a way that is against logic and fair expectations, in order to maximize the likelihood of survival.

\subsubsection{Challenge and feedback}

The theory of psychological flow, suggests that the relationship between challenge and skill determines the engagement level of the player during gameplay. At any given level of skill, lower than equal challenge results in boredom and detachment, while higher than equal challenge results in anxiety, stress and ultimately resignation (Csikszentmihalyi 1975). When challenge is high but within the capabilities of the individual, the result is a state of consciousness characterized by extreme absorption, enjoyment and feelings of achievement (Csikszentmihalyi 1990). In order to grant this experience to players, digital games design has gradually incorporated sophisticated methods of adapting the difficulty level of the game to the skill level of the player. This process is oftentimes mentioned in the literature as scaffolding and empirical evidence has shown that it is linked to higher user engagement and learning (Barzilai and Blau 2014; Chen and Law 2016; Sun et al. 2011)

A common practice to achieve this, is the inclusion of an adjustable difficulty option which allows players to manually adapt the game's difficulty to their skill and experience. An alternate way to achieve the same effect is by utilizing artificial intelligence in order to track the players' performance and adapt the game to their skill level or gameplay style. From a design perspective, this adjustment happens through positive and negative feedback loops in the game. A positive feedback mechanism embedded in the game system is implemented so as to ensure that a certain achievement will make subsequent achievements easier to accomplish. On the contrary, negative feedback mechanisms make sure that the leading players don't get too far ahead. A good 
example of negative feedback response is in the famous game Super Mario Cart. In Super Mario Cart players can randomly obtain weapons by running into question marked boxes with their cart. It is designed however that the chance of a player obtaining a powerful weapon is much higher when they are in the last positions rather when they lead the race. These two powerful mechanisms are always present in welldesigned games and play a catalytic role in maintaining the optimal level of engagement for the player.

Feedback in a similar way is an integral part of every instructional design and can play a catalytic role in enhancing and maintaining the cognitive engagement of learners (Gresalfi and Barnes 2016). Given the complexity and oftentimes intensity of gameplay, digital games implement feedback devices in order to reduce the high cognitive load and uncertainty that the player would otherwise experience (Chang et al. 2017). Both these conditions can cause the disengagement of the player. Uncertainty is an unpleasant feeling that can lead to distraction from the task and is often manifested as a gap between the existing and the desired performance levels (Shute 2008). Similarly, cognitive load theory poses that low prior knowledge regarding a specific domain will generate high cognitive load, since no existing schema is available to process the new information (Moreno 2004). The negative effect of high cognitive load on cognitive engagement (Brünken et al. 2003) is especially true for instructional environments that -much like games- promote exploration, experimentation, interaction and manipulation of objects, or hypotheses testing (Moreno et al. 2001).

Successful digital games try to mitigate these negative effects by delivering timely, frequent, and relevant feedback in order to satisfy the constant need of players for correcting inappropriate strategies, determining the distance and progress towards objectives and identifying their status in the game (Sweetser and Wyeth 2005). The design challenge however is not just delimited in condensing and communicating all the required information to the player in a consistent manner. Empirical evidence in the context of learning environments shows that feedback from external sources tends to interrupt the engagement of students during the activity and inhibit learning (Corno and Snow 1986). It is therefore equally important for the feedback to be incorporated in the game experience in a non-intrusive way.

To illustrate the above design challenge, we can look into two different cases, where designers tried to incorporate feedback in a non-intrusive way. In the famous platform game Abe's Oddyssey, the information regarding the health condition of the character is communicated to the player in a visual way, by altering the looks of the avatar upon deterioration or rejuvenation of his health, in contrast to the common approach of onscreen information display (e.g. an information box tracking the health of the character) (Rouse 2005). The designers tried in this way to remove an obstructive element from the screen in order to avoid disrupting the immersion of the player caused by the limitation of the game-world view. In contrast, the same idea when implemented in the driving game The Getaway failed to maintain the engagement of players because the substitution of a navigation map on screen with a signaling mechanic on the car (the left or right signal light on the car starts flashing right before the player needs to take a turn) proved eventually more cognitively taxing for the players (Rouse 2005).

Evidently feedback devices can influence the cognitive engagement of players and qualities like immediacy, frequency, clarity and relevance can contribute to that. This relationship however proves rather fragile given the capacity of such mechanisms to 
disrupt the immersion and engagement of players. It is therefore deemed crucial to consider the effects of such mechanisms on gameplay when designing or evaluating game-based learning applications.

\subsection{Hedonic game design and user engagement}

Similarly to other forms of art, during gameplay players experience intense imaginative involvement to the degree where the boundaries between themselves and the medium begin to fade. Huizinga (1955: p.10) described the place in space and time where participants create and enter when the game begins as a "magic circle"; a temporary world "within the ordinary world, dedicated to the performance of an act apart". The role of plot and theme in games is to reinforce this "magic circle" by stimulating the imagination of users, and enhancing their emotional engagement. While not all successful digital games have an intricate narrative structure (e.g. Tetris), narrative can be considered as one of the main pillars of educational game effectiveness due to the applied, and often complex nature of these games (Eseryel et al. 2013; Lester et al. 2014). In order to support a desirable level of realism, bridge the game experience to its real-world counterpart and, effectively, facilitate situated and experiential learning, educational games could benefit from the embedding of well-established narrative devices in their design.

The existence of characters and narrative devices in games, when properly implemented, cause identification and empathy that leads to the emotional engagement of users (Bachen et al. 2016; Coplan 2004). Due to the nature of game-play, players are exposed only to the spatiotemporal perspective of their character (they are usually always at the center of the action and their character present in the screen), which is the protagonist. This causes them to process the emotional implications of narrative events from the standpoint of their character (Gernsbacher et al. 1992). As a result, players imaginatively adopt their character's emotional state further reinforcing their suspension of disbelief.

Similarly, the role of aesthetics in digital games is both functional and hedonic. A clear and intuitive game world allows for better navigation and control. A realistic environment makes easier the guessing of its different properties based on knowledge of its real counterpart. For instance, higher degree of fidelity in graphics allows for more accurate representations and manipulation of virtualized real-world objects or places. These elements might be necessary for a particular learning task, potentially influencing the level of knowledge transfer to the real world due to better achieved similarity between the two environments. Similarly, the more convincing the environment is, the more willing the player will be to let go and immerse herself into it. In fact, empirical evidence demonstrates that a high degree of realism in audiovisual elements greatly determines the success of a digital game (e.g. Wood et al. 2004).

Aesthetics however serve another important role besides augmenting humancomputer interaction. They maximize the immersion of players in the game world by providing with captivating sensory stimuli. The prototypical aesthetic experience stimulates intense feelings or emotions and fixates the attention of the participant upon the components of a visual pattern in a way that excludes the awareness of other objects or events (Kubovy 2000 cited in El-Nasr et al. 2007). Graphic representation is one aspect of that but music and sound effects can also reinforce intense pleasurable 
responses by stimulating regions in the brain involved in reward and emotion (Blood and Zatorre 2001). Consequently, besides being important for the semantic operations of games by invoking "cognitive associations between types of music and interpretations of causality, physicality and character" (Whalen 2004), audio elements enhance the emotional engagement of players, support storytelling (e.g. actor voices) and contribute to the stimulation of players' imagination (Byun and Loh 2015). From an aesthetics perspective, however, fidelity is not a necessary condition for player engagement. There are ample examples of modern games that adopted a retro low-fi design and still managed to receive critical acclaim and commercial success (e.g. Papers Please). The key here is utilizing artistic conventions to generate an aesthetically consistent and emotionally powerful audiovisual experience.

All the previously discussed game elements (system mechanics, narrative and aesthetics) facilitate the cognitive and emotional engagement of players by driving them in a condition of psychological flow. Getting players "in the zone" means that they experience intense emotions, high levels of perceived control, focus of attention and cognitive activity. The implications for instructional design are therefore significant since empirical evidence shows that learning in a computer environment correlates with affect (Craig et al. 2004) and that flow significantly influences learning outcomes (Choi et al. 2007; Ghani and Deshpande 1994; Pearce et al. 2005; Webster et al. 1993).

\section{Game design and intrinsic motivation}

Although oftentimes relevant literature uses the terms engagement and motivation interchangeably, existing evidence suggests that they are conceptually distinct phenomena and that the one influences the other (Hektner and Csikszentmihalyi 1996). Engagement captures a player state that is characterized by deep cognitive and emotional absorption that is over once the playing session ends. Intrinsic motivation presents an inner drive that urges the user to get into and continue coming back to the activity. In the context of learning, intrinsic motivation captures the natural inclination towards assimilation, mastery, spontaneous interest, and exploration which are fundamental for cognitive and social development (Ryan and Deci 2000). It is the strongest type of self- motivation and according to the self-determination theory (SDT) at the heart of this form of motivation lie three psychological needs: the need for competence, the need for relatedness and the need for autonomy. Additionally, cognitive evaluation theory (CET) poses that the psychological needs for competence and autonomy can be influenced by socio-contextual factors (e.g. opportunities for selfdirection, feedback, communication, rewards) (Deci and Ryan 1975) which means that they can be influenced by the game design elements that were discussed earlier. Given the strong link between intrinsic motivation and learning, it is important to investigate the ways that a game-based learning environment can fulfill the basic needs of users related to intrinsic motivation: their need for autonomy, relatedness and competence.

\subsection{Need for autonomy}

Perceived autonomy is dependent on the amount of control that players experience during gameplay as well as on the available opportunities for self-expression in the 
game. Digital games typically evoke a sense of personal control by allowing players to select strategies, manage the direction of play, and make meaningful decisions that directly influence outcomes (Garris et al. 2002). In reality, the players never experience complete control. Like with every other type of game, digital games are bound to rules that are largely determined by design (Becker 2007). It can be argued however that the availability of meaningful choices and the discovery of winning strategies through active experimentation, enhances the perceived autonomy of players and is broadly responsible for the enjoyable and intrinsically motivating nature of digital games. Figure 2 illustrates a good example of the way that games achieve the aforementioned "bounded" autonomy. The image depicts the passive skill tree for every character in the MMORPG (massively multiplayer online role-playing game) Path of Exile. Every dot in the picture represent a skill that a player can claim every time they level up their character. Such skills grand the character with special abilities and belong to different domains like intelligence, strength, dexterity etc.

The skills represented by every dot are pre-determined and available for the player to choose since the start of the game. Zooming in the tree provides extra information for every skill and given their starting position (depending on the character's initial setup) every player can form a unique string of skills (they should always be interconnected)

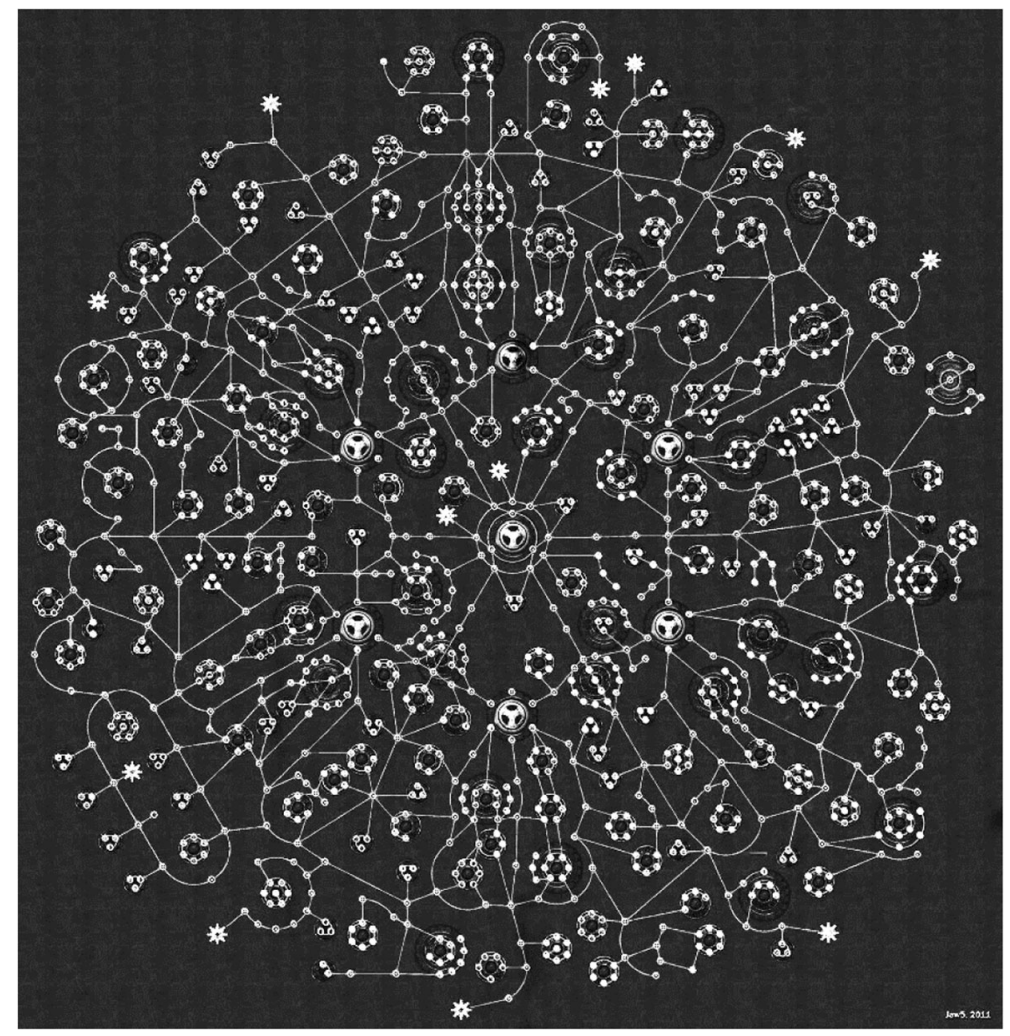

Fig. 2 Macro-view of the passive skill tree available in the MMORPG "Path to Exile". Every white dot represents a different skill that the player can unlock for her character. Zooming in reveals the different requirements and benefits of each skill 
that essentially reflect their strategy to winning the game. Technically, the skill is limited, however, it offers enough meaningful choices for the players to feel in control of their own destiny.

Such an implementation has important implications for learning applications. Empirical findings suggest that some degree of individual control positively influences learning outcomes by enhancing motivation (Kinzie et al. 1988; Skinner et al. 1990) and engagement in metacognitive abilities (e.g. actively monitor one's progress, determine areas of weakness, and adjust learning strategies accordingly) (Schmidt and Ford 2003). When successfully supporting exploration, experimentation, freedom for choice (strategic decision making), self-reflection and self-correction, we would expect instructional digital games to enhance the perceived control of players and consequently lead to higher intrinsic motivation, and consequently learning and knowledge transfer.

Interlinked to the need for control we also find the psychological need for creation and representation of self-identity. Customization of in-game characters (avatar, abilities and stats, class and equipment) and the game interface (layout, color pallet etc.) are trademark mechanisms that games employ in order to gratify the needs of players in terms of self-expression. Allowing players to manipulate their virtual presence in the game environment satisfies not only their need for self-expression, but at the same time reinforces the merge of identity between the player and the game protagonist leading to higher motivation (Birk et al. 2016).

On the one hand, self-expression generates feelings of autonomy and the players' expectations for opportunities of self-expression in virtual environments has increased dramatically in the past couple of decades (Rigby and Ryan 2011). Instructional design can therefore tap in these expectations, enhance the players' perceived autonomy and support higher intrinsic motivation by incorporating such mechanisms in the learning environment.

On the other hand, self-expression supports behavioral changes that are desirable in a learning context. By customizing their virtual presence, learners tend to construct a virtual identity closer to their ideal self, constituting the merge of the two identities easier. That results in higher efficacy as well as behavioral changes due to identification with the in-game character. Empirical evidence shows that changes in the selfrepresentation of individuals in a virtual environment can cause drastic behavioral changes while operating in such an environment (e.g. taller avatars can result in more confidence while more attractive avatars in higher intimacy with confederates) (Yee and Bailenson 2007). Further, such a merge could result in the player adopting the goals, attitudes, and evaluations of the game character (Klimmt et al. 2009). This implies that it is possible to influence the development or adoption of certain beneficial for learning behaviors from the players by scripting them in the in-game characters. The avenue of enhancing learning behaviors by manipulating in game characters is an interesting avenue for future research.

\subsection{Need for competence/achievement}

The need for competence and its interlinked need for achievement constitute the second pillar of intrinsic motivation. The relevance of perceived competence as a component of intrinsic motivation can be traced in Bandura's theory of self-efficacy (Bandura 1997). The theory proposes that the actor's perception of competence in carrying out the required 
behaviors for achieving a desired goal is a key mechanism of human agency (Deci and Ryan 2000). In the context of instructional design, stimulating the perceived competence of learners is a desired quality as it is expected to encourage learners to seek out and invest the necessary effort in order to master developmentally appropriate challenges (Deci and Ryan 1985; Reeve 2009). Perceived competence is the result of an inferential process during which factors like perceived ability, expended effort, task difficulty, external assistance, and patterns of successes and failures are considered (Schunk 1990).

Digital games support this process by keeping the challenge at an optimal level and by providing positive and useful feedback (Nakamura and Csikszentmihalyi 2002; Reeve 2009). The previous part has already illustrated ways through which games maintain optimal challenge during gameplay as well as the role of feedback immediacy, frequency and clarity in sustaining high levels of cognitive engagement in players. The benefits of optimal challenge and certain feedback characteristics however expand beyond engagement, as they can reinforce the perceived competence of players and indirectly influence intrinsic motivation. This is achieved partly through a scaffolding design which as we discussed above allows players to gradually familiarize themselves with the complexity of the virtual environment, provide adaptive challenge and result in higher learning outcomes (Sampayo-Vargas et al. 2013). In the service of this purpose, games often incorporate a tutorial -introductory- chapter at the beginning of the game, an AI regulated level of difficulty, and a hint system that gets activated when the user is perceived as "stuck" in a level. This results in a less steep learning curve that enhances the perceived competence of players as they avoid highly challenging situations when still their mastery level is low and the perceived uncertainty is high.

In a complementary way, the nature of feedback provided appears to play a catalytic role in shaping the perceived competence of players. Empirical evidence suggests that formative feedback, which provides cues on how to perform a task or how to improve oneself, benefits the self-competence of learners (Chan and Lam 2008). In a similar way attributional feedback as well as feedback on goal progress when appropriately implemented appear to enhance self-efficacy (Bandura and Cervone 1983; Relich et al. 1986). Nevertheless, in learning contexts the most encountered type of feedback is outcome based (Johnson et al. 1993). Outcome feedback-scores, performance indicators etc.-, despite its previously discussed contribution to engagement (Csikszentmihalyi 1990), does not always contribute to learning, especially during complex, uncertain tasks that require cognitively rich decision making (Jacoby and Mazursky 1984). In such cases it is important that the player has also access to cognitive-based feedback mechanics like the ones discussed in the previous part-e.g. hints on the process of performing a task or on what underlines response accuracy. The design challenge in this case though, is the embedding of such sources of cognitive feedback in the application, without disrupting the players' state of "suspension of disbelief", which is the optimal condition that game design aims for.

\subsection{Relatedness}

Relatedness expresses the human drive towards forming and maintaining at least a minimum quantity of lasting, positive, and significant interpersonal relationships (Baumeister and Leary 1995). It is a strong condition for sustaining intrinsic motivation and the latest revolution in gaming (massively multiplayer online games, or MMOGs) 
does in fact touch upon this sensitive and very important human need. In essence, these games satisfy the need of players for relatedness by addressing their needs for acknowledgement, support and impact (Rigby and Ryan 2011). Digital games are fundamentally different from traditional media in the sense that characters in the game don't act for, but react to the players (Rigby and Ryan 2011). Through interaction with other players or non-player characters (AIs), the player gains acknowledgement for her actions (e.g. congratulations on her achievements), support during gameplay (e.g. other players or NPCs can assist her in a time of distress) and most importantly see the impact of her action on other characters (either on a reactional level -greeting back-, or on a narrative level -her decision to sacrifice a team member for the great good).

\section{The moderating role of user dispositions}

While the previous parts discussed attributes of game design and how they shape user experience and learning outcomes it is important to consider whether individual differences of users influence the strength of these effects. Personality has recently become an area of interest in the field of information systems with regards to technology acceptance and use (e.g. Barnett et al. 2015; Devaraj et al. 2008). Unfortunately, the role of personality in shaping the effect of game design on user experience and learning has been neglected in the games literature (Nagle et al. 2016). We have already evidence that players adopt different styles when interacting with digital games (Bartle 2006) and our investigations should be extended to learning outcomes and technology acceptance. This part will theoretically discuss the role of specific personality traits in shaping the aforementioned relationships.

Based on previous empirical research on personality traits and academic motivation and performance (e.g. Komarraju and Karau 2005) a set of dispositions that influence the levels of engagement and the overall acceptance of the technology, were identified. Being a novel instructional approach with limited existing counterparts, openness to experience can be considered as a very important trait for user engagement and technology acceptance. Proven to be a valid predictor of training proficiency, openness to experience predicts not only positive attitudes towards learning experiences in general (Barrick and Mount 1991) but also a disposition to accept a new and unfamiliar technology as a means for training (Devaraj et al. 2008). The second important personality trait that could allow for unique variance in acquisition of knowledge is conscientiousness (Barrick and Mount 1991) as it influences the perseverance and dedication of individuals to their learning goals. Finally, goal-orientation, which determines the motives and learning strategies of individuals, is also considered as an important moderator between engagement, motivation, and learning (Dweck 1986).

In addition, due to the second nature of digital games as environments for high immersion and enjoyment two traits were identified that while not associated with academic motivation and performance outcomes, are expect to play a significant role in moderating the effects of instructional design on engagement and motivation. These traits are sensation seeking, which outlines an innate preference for varied, novel, and complex sensations and experiences (Zuckerman 1979) and need for cognition, an individual's tendency to engage in and enjoy effortful cognitive activities (Cacioppo et al. 1996). The above individual characteristics were chosen based on their potential 
influence not only on game effectiveness in terms of learning outcomes but also in terms of technology acceptance.

\subsection{Goal orientation}

People differ substantially in the way they perceive challenge and feedback, or accept novel activities for development. Goal orientation provides a framework that accounts for the aforementioned differences by looking at particular individual dispositions toward developing or demonstrating ability in achievement situations (Dweck and Leggett 1988; C. Dweck 1986; Pintrich 2000b). "The two major classes of goal orientation are: a) a learning goal orientation of seeking to develop competences by acquiring new skills and mastering new situations and b) a performance goal orientation of seeking to demonstrate and validate the adequacy of one's competence by seeking favorable judgments and avoiding negative judgments about one's competence" (Vandewalle 1997). While in a digital game-based learning context we would naturally expect people with a learning goal orientation to feel more intrinsically motivated and consequently achieve higher learning, the role of performance goal orientation is not so straightforward.

As learning goals are typically found to be associated with challenge seeking, an effort/strategy focus, positive affect, and high persistence under difficulty (Dweck and Leggett 1988) such individuals will display high levels of engagement and consciously pursue the mastering of their skills and acquirement of knowledge. On the other hand, performance goal oriented individuals are expected to display lower levels of motivation, avoidance of challenging tasks, negative affect following a failure, limited use of strategy etc. (e.g. Ames 1992). Recent findings however suggest that in certain occasions a performance goal orientation can actually result to better performance and overall achievement (Pintrich 2000a). These findings eventually lead to a distinction between approaching performance goals and avoiding performance goals. Individuals that approach goals have an intrinsic need to demonstrate their ability and outperform others while individuals that avoid goals try not to humiliate themselves and avoid undertaking the task.

Under this light, we would expect players with a learning goal orientation to display a high engagement/ high learning behavior, players with a performance goal orientation to display a high engagement/limited learning behavior and players with an avoid goal orientation a low engagement/low learning behavior. The limitation in the learning ability of performance goal oriented individuals would be the result of not consciously acting towards mastering their skills and knowledge but actually limiting their strategies only to low effort/high gain (in terms of score) ones. That would limit exploration/ experimentation and the direct effect of pedagogical elements onto learning outcomes, however even such an approach will result in indirect (unconscious), yet limited, development of skills and knowledge transfer (typically skill based and affective knowledge). An avoid goal orientation on the other hand is expected to negate the engaging nature of certain game features like feedback and challenge as such elements would be perceived as a threat, and their low persistence in the face of difficulty would quickly lead to disengagement from the activity. Even more so, an avoid goal oriented individual would be more likely to avoid engaging with a novel professional development activity in the first place (Vandewalle 1997). 


\subsection{Openness to experience}

Individuals described as high on the openness-to-experience dimension of personality are typically "[...] imaginative, sensitive to aesthetics, curious, independent thinkers, and amenable to new ideas, experiences and unconventional perspectives" (George and Zhou 2001). Openness constitutes an important variable in the framework, accounting for individual differences to the extent that learners are intrigued by imagining consequences and experimenting with different strategies (McCrae 1987) and emotionally sensitive to art and beauty (McCrae and Sutin 2009), thus enhancing (or in its absence, counteracting) the effect of game features like aesthetics, fantasy and mystery on engagement. More importantly however openness influences the attitude of individuals when entering the training program, giving them a competitive advantage (Goldstein 1986: 70). Being a rather innovative and unique technology for learning, digital games might be treated with skepticism or resistance especially from people that are not very familiar with gaming technology. In this case openness moderates the acceptance of technology and the ability to make the best out of it (Colquitt et al. 2002; Devaraj et al. 2008).

\subsection{Conscientiousness}

Conscientiousness seems to have in indirect relationship to learning outcomes in the context of digital games. As it is traditionally related to qualities like being hardworking, ambitious, persevering and energetic (McCrae and Costa 1987) it has been consistently found to predict higher job performance (Barrick and Mount 1991). When it comes to learning however, Martocchio and Judge (1997) found that while conscientious individuals typically display higher self-efficacy which is a valid predictor of motivation and learning (Zimmerman 2000), conscientiousness also introduces selfdeception - a positively biased perception of someone's actual abilities or accomplishments- which eventually leads to diminishing learning. It seems that the overall correlation of conscientiousness and learning is determined by the magnitude of two effects. In the case of digital games based learning, we would expect individuals high on conscientiousness but with a learning goal orientation to accept the technology and display higher knowledge transfer than those low on conscientiousness. A learning orientation actually grants them the opportunity to transform their hard work and engagement into increased performance and active learning (Bakker et al. 2012). On the other hand, it is possible that when highly conscientious individuals adopt a performance goal orientation the drive to excel and prove their competence is more likely to lead them into self-deception by overestimating their capabilities.

\subsection{Sensation seeking and need for cognition}

Individuals characterized by the trait of sensation seeking typically engage in intense activities that provide them with a good amount of thrill or even danger. Sensation seeking has been typically studied in relation to risk behaviors (e.g. extreme sports, alcohol, high risk sexual behaviors), however it is possible that the trait is also manifested in more disciplined ways (e.g. attaining positions of leadership due the high intensity that such experiences entail). Given that many modern digital games are designed to deliver considerable amounts of adrenaline, intense emotions and 
complexity, it is natural to expect that players with a high sensation seeking disposition would be drawn to them and practically become more engaged during gameplay. In fact, early empirical findings show that individuals high on sensation seeking, experience higher engagement when involved in an action-filled first person shooter game compared to those that exhibit low levels of the trait, with the reverse being true for more casual games (e.g. Tetris) (Ravaja et al. 2004). In essence this means that modern action-filled blockbusters may be considered as pinnacles of immersive design, however it could be that they elicit these higher levels of engagement or absorption only on a fraction of gamers.

In a similar vein, we would expect individuals that display a higher need for cognition to be more intrinsically motivated to engage with a cognitively demanding and challenging game environment. Such individuals are generally characterized by active, exploring minds, and they naturally tend to seek out stimuli or tasks that require reasoning or problem solving (Cacioppo et al. 1996). Such behaviors can lead to feelings of higher control or mastery over an individual's world, and allow for a greater sense of self-satisfaction (Osberg 1987). One conceptualization of need for cognition in particular poses that it may lead to feelings of self-esteem, competence and worth (Osberg 1987). Given its self-motivating nature, we would expect need for cognition to influence the intrinsic motivation of players by moderating the effect of instructional design on satisfying their needs for competence and autonomy.

\section{Conclusion}

As Proserpio and Gioia (2007) aptly argue, teaching and learning pedagogies should always be aligned with the wider technical and social changes of the contemporary reality. As expected, education scholars were intrigued by the current digital game (r)evolution primarily due to the fact that: a) gaming technology has reached a level of sophistication that can offer new possibilities for instructional design and $b$ ) we welcome for the first time in our academic institutions and workplaces a generation that developed a particular set of dispositions and expectations due to their extensive interaction with digital game platforms (Brown and Thomas 2008; Carstens and Beck 2005; Proserpio and Gioia 2007). This occurrence coincides with the exponential growth of the gaming industry and its consumer base (De Prato et al. 2014), as well as with the successful penetration of digital game elements in different facets of our reality, be that communication, collaboration, learning, consumption or entertainment, via the recently emerged phenomenon of gamification (Zichermann and Cunningham 2011).

Digital games provide with multiple opportunities for educators, however, harmonically blending pedagogy with gaming technology is not a small feat and requires a very thorough understanding of the interplay between game mechanics, motivation, engagement, subjective user characteristics and their effect on learning behavior. To this end, this paper tried to delineate the function of key design elements that while considered the cornerstones of motivation and engagement, are often insufficiently implemented in the design of instructional digital games. At the same time, it drew attention to the role of user dispositions in technology acceptance and their effect on engagement and learning outcomes, a discussion that is surprisingly absent from the literature. 
In particular, we theoretically established that: a) Proximal goals are expected to have a higher impact on sustaining the cognitive engagement of the player than distant goals, b) the incorporation of uncertainty in the game's reward system is expected to further enhance the cognitive engagement of players, c) timely and frequent feedback is expected to enhance the cognitive engagement of users when introduced in a nonintrusive way, and d) adaptable challenge levels are expected to sustain higher levels of cognitive engagement throughout the gameplay experience. Moreover, we discussed how hedonic game elements support the engagement of users, establishing that: e) narrative devices that identify the player with her in-game character(s), and the manipulation of tension and climaxes as play progresses, can result in a higher emotional engagement for the users of instructional video games, and f) aesthetically appealing audiovisual elements in instructional games are expected to enhance the immersion of players.

In addition, the paper revealed the relationship between game design elements and intrinsic motivation, highlighting therefore the conceptual difference between motivation and engagement and how they relate to each other. In particular we theoretically discussed how: g) the satisfaction of the psychological need for autonomy through increased levels of perceived control and provided opportunities for self-representation and expression, is expected to enhance the intrinsic motivation of players, h) the existence of optimal challenge and clear and timely cognitive feedback are expected to satisfy the intrinsic need of players for competence and lead to higher intrinsic motivation, and i) facilitating the development of game related online communities and enabling various types of interaction and selforganization among players is be expected to satisfy their intrinsic need for relatedness leading to higher levels of intrinsic motivation.

Finally, our paper brought attention to the important role of user personality and its interaction with game design. This is a very promising area of research that has been largely neglected by the literature so far. In particular we propose that: $\mathrm{j}$ ) while both performance and goal orientated individuals would be expected to display high levels of intrinsic motivation and engagement during game-play, learning oriented individuals are expected to achieve higher learning outcomes, compared to performance oriented ones, k) players with high levels of openness to experience are expected to achieve higher levels of engagement and user acceptance, 1) conscientious individuals that also possess a learning goal orientation are expected to achieve higher learning outcomes contrary to individuals that display high levels of conscientiousness but possess a performance goal orientation, m) sensation seeking moderates the relationship between instructional design and engagement. Players high in sensation seeking are expected to feel more absorbed when introduced in a novel, intense and complex digital game environment compared to a more relaxed and casual one. In contrast, players low in sensation seeking are expected to feel more engaged when playing in more relaxed casual game environments. Lastly, n) need for cognition is expected to moderate the relationship between instructional game design elements and intrinsic motivation. Individuals that possess this characteristic are expected to feel higher satisfaction when engaging in a cognitively demanding digital game environment, therefore the effect of instructional game design elements on intrinsic motivation will be higher. The opposite is true for individuals that don't possess this characteristic. 
Open Access This article is distributed under the terms of the Creative Commons Attribution 4.0 International License (http://creativecommons.org/licenses/by/4.0/), which permits unrestricted use, distribution, and reproduction in any medium, provided you give appropriate credit to the original author(s) and the source, provide a link to the Creative Commons license, and indicate if changes were made.

\section{References}

Ames, C. (1992). Classrooms: Goals, structures, and student motivation. Journal of Educational Psychology, 84(3), 261-271.

Anselme, P. (2013). Dopamine, motivation, and the evolutionary significance of gambling-like behaviour. Behavioural Brain Research, 256, 1-4.

Bachen, C. M., Hernández-Ramos, P., Raphael, C., \& Waldron, A. (2016). How do presence, flow, and character identification affect players' empathy and interest in learning from a serious computer game? Computers in Human Behavior, 64, 77-87.

Bakker, A. B., Demerouti, E., \& Brummelhuis, L. L. (2012). Work engagement, performance, and active learning: The role of conscientiousness. Journal of Vocational Behavior, 80(2), 555-564.

Bandura, A. (1997). Self-efficacy: The exercise of control. New York: Worth Publishers.

Bandura, A., \& Cervone, D. (1983). Self-evaluative and self-efficacy mechanisms governing the motivational effects of goal systems. Journal of Personality and Social Psychology, 45(5), 1017-1028.

Bandura, A., \& Schunk, D. (1981). Cultivating competence, self-efficacy, and intrinsic interest through proximal self-motivation. Journal of Personality and Social Psychology, 41(3), 586-598.

Barnett, T., Pearson, A. W., Pearson, R., \& Kellermanns, F. W. (2015). Five-factor model personality traits as predictors of perceived and actual usage of technology. European Journal of Information Systems, 24(4), 374-390.

Barrick, M. R., \& Mount, M. K. (1991). The big five personality dimensions and job performance: A metaanalysis. Personnel Psychology, 44(1), 1-26.

Bartle, R. A. (2006). Hearts, clubs, diamonds, spades: Players who suit MUDs. In K. Salen \& E. Zimmerman (Eds.), The game design reader: A rules of play anthology (pp. 754-787). MIT Press.

Barzilai, S., \& Blau, I. (2014). Scaffolding game-based learning: Impact on learning achievements, perceived learning, and game experiences. Computers \& Education, 70, 65-79.

Baumeister, R. F., \& Leary, M. R. (1995). The need to belong: desire for interpersonal attachments as a fundamental human motivation. Psychological Bulletin, 117(3), 497-529.

Becker, K. (2007). Pedagogy in commercial video games. In D. Gibson, C. Aldrich, \& M. Prensky (Eds.), Games and simulations in online learning: Research and development frameworks (pp. 21-47). Hershey: Information Science.

Birk, M. V., Atkins, C., Bowey, J. T., \& Mandryk, R. L. (2016). Fostering intrinsic motivation through avatar identification in digital games. Proceedings of the 2016 CHI Conference on Human Factors in Computing Systems-CHI'16, 2982-2995.

Bjorklund, D. F., \& Pellegrini, A. D. (2010). Evolutionary perspectives on social development. In P. K. Smith \& C. H. Hart (Eds.), The Wiley-Blackwell handbook of childhood social development (pp. 64-81). Oxford: Wiley.

Blood, A. J., \& Zatorre, R. J. (2001). Intensely pleasurable responses to music correlate with activity in brain regions implicated in reward and emotion. Proceedings of the National Academy of Sciences of the United States of America, 98(20), 11818-11823.

Brown, J. S., \& Thomas, D. (2008). The gamer disposition. Harvard Business Review, 86(2), 28.

Boyle, E., Connolly, T. M., \& Hainey, T. (2011). The role of psychology in understanding the impact of computer games. Entertainment Computing, 2(2), 69-74.

Brünken, R., Plass, J., \& Leutner, D. (2003). Direct measurement of cognitive load in multimedia learning. Educational Psychologist, 38(1), 53-61.

Byun, J., \& Loh, C. S. (2015). Audial engagement: Effects of game sound on learner engagement in digital game-based learning environments. Computers in Human Behavior, 46, 129-138.

Cacioppo, J. T., Petty, R. E., Feinstein, J., \& Jarvis, W. B. G. (1996). Dispositional differences in cognitive motivation: The life and times of individuals varying in need for cognition. Psychological Bulletin, 119(2), 197-253.

Cairns, P., Cox, A. L., Day, M., Martin, H., \& Perryman, T. (2013). Who but not where: The effect of social play on immersion in digital games. International Journal of Human-Computer Studies, 71(11), 1069-1077.

Campbell, J. (2003). The Hero's Journey: Joseph Campbell on His Life and Work. Novato: New World Library.

Carstens, A., \& Beck, J. (2005). Get ready for the gamer generation. TechTrends, 49(3), 22-25. 
Chan, J. C. Y., \& Lam, S. (2008). Effects of different evaluative feedback on students' self-efficacy in learning. Instructional Science, 38(1), 37-58.

Chang, C. C., Liang, C., Chou, P. N., \& Lin, G. Y. (2017). Is game-based learning better in flow experience and various types of cognitive load than non-game-based learning? Perspective from multimedia and media richness. Computers in Human Behavior, 71, 218-227.

Chen, C. H., \& Law, V. (2016). Scaffolding individual and collaborative game-based learning in learning performance and intrinsic motivation. Computers in Human Behavior, 55, 1201-1212.

Choi, D. H., Kim, J., \& Kim, S. H. (2007). ERP training with a web-based electronic learning system: The flow theory perspective. International Journal of Human-Computer Studies, 65(3), 223-243.

Clark, D. B., Tanner-Smith, E. E., \& Killingsworth, S. S. (2016). Digital games, design, and learning: A systematic review and meta-analysis. Review of Educational Research, 86(1), 79-122.

Colquitt, J., Hollenbeck, J. R., Ilgen, D. R., LePine, J., \& Sheppard, L. (2002). Computer-assisted communication and team decision-making performance: The moderating effect of openness to experience. Journal of Applied Psychology, 87(2), 402-410.

Coplan, A. (2004). Empathic engagement with narrative fictions. The Journal of Aesthetics and Art Criticism, 62(2), 141-152.

Corno, L., \& Snow, R. E. (1986). Adapting teaching to individual differences among learners. In Handbook of research on teaching (3rd ed., pp. 605-629). New York: Macmillan.

Craig, S., Graesser, A., Sullins, J., \& Gholson, B. (2004). Affect and learning: An exploratory look into the role of affect in learning with AutoTutor. Journal of Educational Media, 29(3), 241-250.

Csikszentmihalyi, M. (1975). Beyond boredom and anxiety: Experiencing flow in work and play. San Fransisco: Jossey-Bass.

Csikszentmihalyi, M. (1990). Flow: The psychology of optimal experience. New York: Harper-Perennial.

Deci, E., \& Ryan, R. (1975). Cognitive evaluation theory and some comments on the calder and staw critique. Journal of Personality and Social Psychology, 31(1), 81-85.

Deci, E. L., \& Ryan, R. M. (1985). Intrinsic motivation and self-determination in human behavior. New York: Pantheon.

Deci, E., \& Ryan, R. (2000). The“what" and" why" of goal pursuits: Human needs and the self-determination of behavior. Psychological Inquiry, 11(4), 227-268.

De Prato, G., Feijoo, C., \& Simon, J.-P. (2014). Innovations in the video game industry: Changing global markets. Communications \& Strategies, 2(94), 17-39.

DeSmet, A., Van Ryckeghem, D., Compernolle, S., Baranowski, T., Thompson, D., Crombez, G., ... De Bourdeaudhuij, I. (2014). A meta-analysis of serious digital games for healthy lifestyle promotion. Preventive Medicine, 69, 95-107.

Devaraj, S., Easley, R. F., \& Crant, J. M. (2008). How does personality matter? Relating the five-factor model to technology acceptance and use. Information Systems Research, 19(1), 93-105.

Driscoll, M. P. (2005). Psychology of learning for instruction (3rd ed.). Boston: Pearson Education, Allyn and Bacon.

Dweck, C. (1986). Motivational processes affecting learning. American Psychologist, 41(5), 1040-1048.

Dweck, C. S., \& Leggett, E. L. (1988). A social cognitive approach to motivation and personality. Psychological Review, 95(2), 256-273.

Earp, J., Ott, M., Popescu, M., Romero, M., \& Usart, M. (2014). Supporting human capital development with serious games: An analysis of three experiences. Computers in Human Behavior, 30, 715-720.

El-Nasr, M. S., Niedenthal, S., Knez, I., Almeida, P., \& Zupko, J. (2007). Dynamic lighting for tension in games. Game Studies, 7(1).

Erhel, S., \& Jamet, E. (2013). Digital game-based learning: Impact of instructions and feedback on motivation and learning effectiveness. Computers and Education, 67, 156-167.

Eseryel, D., Law, V., Ifenthaler, D., Ge, X., \& Miller, R. (2013). An investigation of the interrelationships between motivation, engagement, and complex problem solving in game-based learning. Educational Technology and Society, 17(1), 42-53.

Fredricks, J., Blumenfeld, P. C., \& Paris, H. (2004). School engagement: Potential of the concept, state of the evidence. Review of Educational Research, 74(1), 59-109.

Garris, R., Ahlers, R., \& Driskell, J. E. (2002). Games, motivation, and learning: A research and practice model. Simulation \& Gaming, 33(4), 441-467.

Gentile, D. (2009). Pathological video-game use among youth ages 8 to 18: A national study. Psychological Science, 20(5), 594-602.

George, J. M., \& Zhou, J. (2001). When openness to experience and conscientiousness are related to creative behavior: An international approach. Journal of Applied Psychology, 86(3), 513-524.

Gernsbacher, M. A., Goldsmith, H. H., \& Robertson, R. R. W. (1992). Do readers mentally represent characters' emotional states? Cognition \& Emotion, 6(2), 89-111. 
Ghani, J. A., \& Deshpande, S. P. (1994). Task characteristics and the experience of optimal flow. The Journal of Psychology, 128(4), 381-391.

Goldstein, I. L. (1986). Training in organizations: Needs assessment, development, and evaluation (2nd ed.). Pacific Grove: Brooks/Cole.

Granic, I., Lobel, A., \& Engels, R. C. M. E. (2014). The benefits of playing video games. The American Psychologist, 69(1), 66-78.

Gresalfi, M. S., \& Barnes, J. (2016). Designing feedback in an immersive videogame: supporting student mathematical engagement. Educational Technology Research and Development, 64(1), 65-86.

Hamari, J., Shernoff, D. J., Rowe, E., Coller, B., Asbell-Clarke, J., \& Edwards, T. (2016). Challenging games help students learn: An empirical study on engagement, flow and immersion in game-based learning. Computers in Human Behavior, 54, 170-179.

Hektner, J. M., \& Csikszentmihalyi, M. (1996). A longitudinal exploration of flow and intrinsic motivation in adolescents. Paper presented at the annual meeting of the American Educational Research Association, New York City.

Howard-Jones, P., \& Demetriou, S. (2008). Uncertainty and engagement with learning games. Instructional Science, 37(6), 519-536.

Huang, W. H. (2011). Evaluating learners' motivational and cognitive processing in an online game-based learning environment. Computers in Human Behavior, 27(2), 694-704.

Huizinga, J. (1955). Homo Ludens: A study of the play-element in culture. Boston: The Beacon Press.

Jacoby, J., \& Mazursky, D. (1984). When feedback is ignored: Disutility of outcome feedback. Journal of Applied Psychology, 69(3), 531-545.

Johnson, D., Perlow, R., \& Pieper, K. F. (1993). Differences in task performance as a function of type of feedback: Learning- oriented versus performance-oriented feedback. Journal of Applied Social Psychology, 23(4), 303-320.

Juul, J. (2005). Half-Real: Video games between real rules and fictional worlds. Cambridge: The MIT Press.

Kark, R. (2011). Games managers play: Play as a form of leadership development. Academy of Management Learning and Education, 10(3), 507-527.

Kim, B., Park, H., \& Baek, Y. (2009). Not just fun, but serious strategies: Using meta-cognitive strategies in game-based learning. Computers \& Education, 52(4), 800-810.

Kinzie, M. B., Sullivan, H. J., \& Berdel, R. L. (1988). Learner control and achievement in science computerassisted instruction. Journal of Educational Psychology, 80(3), 299-303.

Kirschner, P., Sweller, J., \& Clark, R. (2006). Why minimal guidance during instruction does not work: An analysis of the failure of constructivist, discovery, problem-based, experiential, and inquiry-based teaching. Educational Psychologist, 41(2), 75-86.

Kivetz, R., Urminsky, O., \& Zheng, Y. (2006). Resurrected : The goal-gradient hypothesis purchase goal acceleration, illusionary retention and customer progress. Journal of Marketing Research, 43(1), 39-58.

Klimmt, C., Hefner, D., \& Vorderer, P. (2009). The video game experience as "true" identification: A theory of enjoyable alterations of players' self-perception. Communication Theory, 19(4), 351-373.

Komarraju, M., \& Karau, S. J. (2005). The relationship between the big five personality traits and academic motivation. Personality and Individual Differences, 39(3), 557-567.

Krathwohl, D. R. (2002). A revision of Bloom's taxonomy: An overview. Theory Into Practice, 41(4), 212-218.

Kubovy, M. (2000). Visual aesthetics. In A. E. Kazdin (Ed.), Encyclopedia of psychology. New York: Oxford University Press.

Lainema, T., \& Makkonen, P. (2003). Applying constructivist approach to educational business games: Case REALGAME. Simulation \& Gaming, 34(1), 131-149.

Lee, K. M., Park, N., \& Jin, S.-A. (2006). Narrative and interactivity in computer games. In P. Vorderer \& B. Jennings (Eds.), Playing video games: Motives, responses, and consequences (pp. 259-274). Mahwah: Lawrence Erlbaum Associates Publishers.

Lester, J. C., Spires, H. A., Nietfeld, J. L., Minogue, J., Mott, B. W., \& Lobene, E. V. (2014). Designing gamebased learning environments for elementary science education: A narrative-centered learning perspective. Information Sciences, 264, 4-18.

Lewis-Evans, B. (2013). Dopamine and games - Liking, learning, or wanting to play?

Locke, E. a., \& Latham, G. P. (2004). What should we do about motivation theory? Six recommendations for the twenty-first century. The Academy of Management Review, 29(3), 388.

Locke, E., Shaw, K. N., Saari, L. M., \& Latham, G. P. (1981). Goal setting and task performance: 1969-1980. Psychological Bulletin, 90(1), 125-152.

Malone, T. W. (1981). Toward a theory of intrinsically motivating instruction•. Cognitive Science, 5(4), 333-369. 
Malone, T., \& Lepper, M. (1987). Making learning fun: A taxonomy of intrinsic motivations for learning. In R. E. Snow \& M. J. Farr (Eds.), Aptitude, learning and instruction III: Conative and affective process analyses (Vol. 98). Hillsdale: N.J.: Erlbaum.

Martocchio, J. J., \& Judge, T. A. (1997). Relationship between conscientiousness and learning in employee training: mediating influences of self-deception and self-efficacy. The Journal of Applied Psychology, 82(5), 764-773.

Mayer, R. E. (2004). Should there be a three-strikes rule against pure discovery learning? The case for guided methods of instruction. The American Psychologist, 59(1), 14-19.

McCrae, R. R. (1987). Creativity, divergent thinking, and openness to experience. Journal of Personality and Social Psychology, 52(6), 1258-1265.

McCrae, R., \& Costa, P. (1987). Validation of the five-factor model of personality across instruments and observers. Journal of Personality and Social Psychology, 52(1), 81-90.

McCrae, R., \& Sutin, A. (2009). Openness to experience. In M. R. Leary \& R. H. Hoyle (Eds.), Handbook of Individual Differences in Social Behavior (pp. 257-273). New York: Guilford Press.

McKernan, B., Martey, R. M., Stromer-Galley, J., Kenski, K., Clegg, B. A., Folkestad, J. E., ... Strzalkowski, T. (2015). We don't need no stinkin' badges: The impact of reward features and feeling rewarded in educational games. Computers in Human Behavior, 45, 299-306.

Merchant, Z., Goetz, E. T., Cifuentes, L., Keeney-Kennicutt, W., \& Davis, T. J. (2014). Effectiveness of virtual reality-based instruction on students' learning outcomes in K-12 and higher education: A meta-analysis. Computers \& Education, 70, 29-40.

Miller, C. S., Lehman, J. F., \& Koedinger, K. R. (1999). Goals and learning in microworlds. Cognitive Science, 23(3), 305-336.

Moreno, R. (2004). Decreasing cognitive load for novice students: Effects of explanatory versus corrective feedback in discovery-based multimedia. Instructional Science, 32(1/2), 99-113.

Moreno, R., Mayer, R. E., Spires, H. A., \& Lester, J. C. (2001). The case for social agency in computer-based teaching : Do students learn more deeply when they interact with animated pedagogical agents? Cognition and Instruction, 19(February 2015), 177-213.

Nacke, L. E., Grimshaw, M. N., \& Lindley, C. A. (2010). More than a feeling: Measurement of sonic user experience and psychophysiology in a first-person shooter game. Interacting with Computers, 22(5), 336-343.

Nagle, A., Wolf, P., \& Riener, R. (2016). Towards a system of customized video game mechanics based on player personality: Relating the Big Five personality traits with difficulty adaptation in a first-person shooter game. Entertainment Computing, 13, 10-24.

Nakamura, J., \& Csikszentmihalyi, M. (2002). The concept of flow. In C. R. Snyder \& S. J. Lopez (Eds.), Handbook of positive psychology (pp. 89-105). New York: Oxford University Press.

Osberg, T. M. (1987). The convergent and discriminant validity of the need for cognition scale. Journal of Personality Assessment, 51(3), 441-450.

Pearce, J. M., Ainley, M., \& Howard, S. (2005). The ebb and flow of online learning. Computers in Human Behavior, 21(5), 745-771.

Pellis, S. M., \& Pellis, V. C. (2007). Rough-and-Tumble development play of the social. Current Directions in Psychological Science, 16(2), 95-98.

Piaget, J. (1962). Play, dreams and imitation in childhood. New York: Norton.

Pines, A. L. (1985). Toward a taxonomy of conceptual relations and the implications for the evaluation of cognitive structures. In L. H. T. West \& A. L. Pines (Eds.), Cognitive Structure and Conceptual Change. New York: Academic Press, Inc..

Pintrich, P. R. (2000a). Multiple goals, multiple pathways: The role of goal orientation in learning and achievement. Journal of Educational Psychology, 92(3), 544-555.

Pintrich, P. R. (2000b). The role of goal orientation in self-regulated learning. In M. Boekaerts, P. R. Pintrich, \& M. Zeidner (Eds.), Handbook of self-regulation (pp. 451-502). San Diego: Academic Press.

Plass, J. L., Homer, B. D., \& Kinzer, C. K. (2015). Foundations of game-based learning. Educational Psychologist, 50(4), 258-283.

Proserpio, L., \& Gioia, D. (2007). Teaching the virtual generation. Academy of Management Learning \& Education, 6(1), 69-80.

Qian, M., \& Clark, K. R. (2016). Game-based Learning and 21st century skills: A review of recent research. Computers in Human Behavior, 63, 50-58.

Qin, H., Rau, P. L. P., \& Salvendy, G. (2010). Effects of different scenarios of game difficulty on player immersion. Interacting with Computers, 22(3), 230-239.

Ravaja, N., Salminen, M., Holopainen, J., Saari, T., Laarni, J., \& Järvinen, A. (2004). Emotional response patterns and sense of presence during video games: potential criterion variables for game design. In 
Proceedings of the third Nordic conference on Human-computer interaction (pp. 339-347). New York: ACM.

Reeve, J. (2009). Understanding motivation and emotion (5th ed.). New York: John Wiley \& Sons Inc.

Reeves, B., \& Read, L. J. (2009). Total engagement: Using games and virtual worlds to change the way people work and businesses compete. Boston: Harvard Business Press.

Relich, J., Debus, R., \& Walker, R. (1986). The mediating role of attribution and self-efficacy variables for treatment effects on achievement outcomes. Contemporary Educational Psychology, 11(3), 195-216.

Rigby, C. S., \& Ryan, R. M. (2011). Glued to games: How video games draw us in and hold us spellbound. Santa Barbara: ABC-CLIO, LLC.

Ronimus, M., Kujala, J., Tolvanen, A., \& Lyytinen, H. (2014). Children's engagement during digital gamebased learning of reading: The effects of time, rewards, and challenge. Computers and Education, 71, 237-246.

Rooney, P. (2012). A theoretical framework for serious game design. International Journal of Game-Based Learning, 2(4), 41-60.

Rouse, R. I. (2005). Game design: Theory \& practice (2nd ed.). Plano: Wordware Publishing, Inc.

Ryan, R. M., \& Deci, E. L. (2000). Self-determination theory and the facilitation of intrinsic motivation, social development, and well-being. The American Psychologist, 55(1), 68-78.

Sampayo-Vargas, S., Cope, C. J., He, Z., \& Byrne, G. J. (2013). The effectiveness of adaptive difficulty adjustments on students' motivation and learning in an educational computer game. Computers and Education, 69, 452-462.

Savery, J., \& Duffy, T. (1996). Problem based learning: An instructional model and its constructivist framework. In B. G. Wilson (Ed.), Constructivist learning environments: Case studies in instructional design (pp. 135-148). Englewood Cliffs: Educational Technology Publications Inc.

Schmidt, A., \& Ford, J. (2003). Learning within a learner control training environment: The interactive effects of goal orientation and metacognitive instruction on learning outcomes. Personnel Psychology, 56(2), 405-429.

Schunk, D. (1990). Goal setting and self-efficacy during self-regulated learning. Educational Psychologist, 25(1), 71-86.

Shute, V. J. (2008). Focus on formative feedback. Review of Educational Research, 78(1), 153-189.

Simons, J. (2007). Narrative, games, and theory. Game Studies, 7(1).

Skinner, E., Wellborn, J. G., \& Connell, J. P. (1990). What it takes to do well in school and whether I've got it: A process model of perceived control and children's engagement and achievement in school. Journal of Educational Psychology, 82(1), 22-32.

Smuts, A. (2005). Are video games art? Contemporary Aesthetics, 3.

Sun, C.-T., Wang, D.-Y., \& Chan, H.-L. (2011). How digital scaffolds in games direct problem-solving behaviors. Computers \& Education, 57(3), 2118-2125.

Sweetser, P., \& Wyeth, P. (2005). GameFlow: a model for evaluating player enjoyment in games. Computers in Entertainment (CIE), 3(3), 1-24.

Takahashi, D. (2013). With a mobile boom, learning games are a \$1.5B market headed toward \$2.3B by 2017. www.venturebeat.com.

Tsai, F. H., Tsai, C. C., \& Lin, K. Y. (2015). The evaluation of different gaming modes and feedback types on gamebased formative assessment in an online learning environment. Computers and Education, 81, 259-269.

Vandewalle, D. (1997). Development and validation of a work domain goal orientation instrument. Educational and Psychological Measurement, 57(6), 995-1015.

Van Merrienboer, J. J., \& Sweller, J. (2005). Cognitive load theory and complex learning: recent developments and future directions. Educational Psychology Review, 17(2), 147-177.

Vygotsky, L. S. (1978). Mind in society. Cambridge: Harvard University Press.

Webster, J., Trevino, L. K., \& Ryan, L. (1993). The dimensionality and correlates of flow in human-computer interactions. Computers in Human Behavior, 9(4), 411-426.

Whalen, Z. (2004). Play along - An approach to videogame music. Game Studies, 4(1).

Whitton, N. (2010). Game engagement theory and adult learning. Simulation \& Gaming, 42(5), 596-609.

Wood, R. T., Griffiths, M. D., Chappell, D., \& Davies, M. N. O. (2004). The structural characteristics of video games: a psycho-structural analysis. Cyberpsychology \& Behavior: The Impact of the Internet, Multimedia and Virtual Reality on Behavior and Society, 7(1), 1-10.

Yee, N., \& Bailenson, J. (2007). The Proteus effect: The effect of transformed self-representation on behavior. Human Communication Research, 33(3), 271-290.

Zichermann, G., \& Cunningham, C. (2011). Gamification by design: Implementing game mechanics in web and mobile apps. Sebastopol, CA: O'Reily Media Inc. 
Zimmerman, B. (2000). Self-efficacy: An essential motive to learn. Contemporary Educational Psychology, 25(1), 82-91.

Zimmerman, E., \& Salen, K. (2003). Rules of play: Game design fundamentals. Boston: MIT Press.

Zuckerman, M. (1979). Sensation seeking: Beyond the optimal level of arousal. Hillsdale: Erlbaum. 